\title{
Comunicação educativa e educação para o lazer: os super-heróis dos quadrinhos nas aulas de educação física
}

\author{
Cinthia Lopes da Silva* \\ Joan Ferrés i Prats**
}

\begin{abstract}
Resumo
Dentre os estudantes brasileiros do Ensino Fundamental, muitos não participam efetivamente das aulas de Educação Física por questões de ordem metodológica, de mediação didática e de conhecimento. Assim, o presente trabalho teve como objetivo analisar a eficácia de uma proposta pedagógica que parte dos estudos da Comunicação Educativa (baseada na neurociência) e da educação para o lazer. Participaram da pesquisa 20 estudantes de uma escola pública do estado de São Paulo, com idades entre 13 e 14 anos. A pesquisa é qualitativa. Foram utilizados diário de campo e observações. Resultados: novas habilidades corporais foram aprendidas pelos alunos dentro do contexto das histórias em quadrinhos de super-heróis e os estudantes deram indícios de terem desenvolvido uma atitude crítica e criativa.

Palavras-chave: Educação Física, Lazer, Educação, Comunicação.
\end{abstract}

\section{Educational Communication and Education For Leisure: The Super Heroes of the Comic Books In Physical Education Classes}

\begin{abstract}
Many Brazilian students in Elementary School do not take part in Physical Education classes effectively because of various reasons such as matters of methodology issues, didactic mediation and knowledge. So, the present work had the objective of analyzing the effectiveness of a pedagogical proposal from Educational Communication (based on neuroscience) and education for leisure. 20 students from a public school in the state of São Paulo between 13 and 14 years old participated in the research. The research is a qualitative study. A field research and observations were used. Results: new body skills were learned by the students within the super heroes comic books context and the students have shown signs of having developed a critical and creative attitude.
\end{abstract}

Keywords: Physical Education, Leisure, Education, Communication.

\section{Introdução}

Os maiores índices de evasão escolar na Educação Básica brasileira ocorrem nos anos finais do Ensino Fundamental, segundo Brasil (2014), e em decorrência de problemas relacionados a questões didático-metodológicas. No caso das aulas de Educação Física muitos alunos não possuem uma participação efetiva em tais aulas, por não gostarem da disciplina, considerando-a chata, monótona e pouco atrativa (Darido, 2004)). Por outro lado, vemos a necessidade dos alunos da Educação Básica terem maior conhecimento e apreciação das práticas corporais, incluindo-as no seu dia a dia, como parte das atividades do contexto do lazer e também como forma de cuidado com a saúde. O conhecimento acerca das práticas corporais poderá ampliar as possibilidades de vivências dos sujeitos dos conteúdos do lazer, contribuindo para que tenham uma visão reflexiva acerca dos padrões corporais de beleza, do esporte e das demais práticas corporais tanto do ponto de vista da vivência como da apreciação das mesmas. A mídia, por exemplo, é uma instituição que frequentemente difunde um conjunto de significados relacionados ao corpo e às práticas corporais incentivando os sujeitos ao consumo de produtos e de práticas para que se obtenha mudanças corporais (Rossi Filho, Origuela \& Silva, 2016).

* Professora e Pesquisadora da Universidade Metodista de Piracicaba na Graduação em Educação Física e no PPG em Ciências do Movimento Humano. Mestre e Doutora pela UNICAMP.

** Professor Doutor da Universitat Pompey Fabra/Barcelona/Espanha. 
As histórias em quadrinhos (HQ) de super-heróis que são produções da arte e da mídia e são exemplos de como padrões corporais de beleza são difundidos no meio em que se vive. Os super-heróis são pessoas com certas habilidades e padrões corporais - atlético (super-heróis) e de corpos magros e esguios (super-heroínas) e, em geral, alguma deformação é atribuída aos personagens vilões. As HQ e filmes de super-heróis também difundem valores éticos e morais, tais como os super-heróis são os que salvam as pessoas, são as pessoas do bem, os vilões são os inimigos, os que fazem o mal. Essas associações influenciam de certa forma o imaginário das crianças e jovens e é necessária uma mediação acerca dos significados atribuídos aos super-heróis para que os sujeitos desenvolvam uma atitude crítico e criativa (Rossi Filho, Origuela \& Silva, 2016).

$\mathrm{Na}$ Educação Física há várias publicações com objetivo de discussão da mídia e propostas de intervenção no âmbito escolar (Pires, 2002; Betti, 2006; Diniz, Rodrigues \& Darido, 2012), sendo o diferencial da presente investigação realizar uma experiência pedagógica fundamentada na Comunicação Educativa (relacionada a mediações pedagógicas acerca das produções da mídia, aqui no caso as HQ). Algumas publicações baseadas nessa abordagem são: Silva \& Ferrés i Prats (2020) e Silva \& Ferrés i Prats (2019) e na educação para o lazer, tendo como tema das aulas as HQ de super-heróis. Como finalidade das aulas consideramos tanto os conhecimentos acerca da cultura corporal de movimento (jogo, esporte, dança, luta, ginástica) como dos elementos e conteúdos do lazer, dentre os quais os fisicoesportivos (esportes e demais práticas corporais, passeios e pesca). Outros conteúdos do lazer (manual, intelectual, artístico, social, turístico) também devem ser considerados em uma proposta de educação para o lazer, no entanto, o predomínio na presente experiência pedagógica é de atividades relacionadas ao conteúdo fisicoesportivo, por esse ser a especificidade das aulas de Educação Física.

Um dos pressupostos da Comunicação Educativa, segundo Ferrés i Prats $(2000,2014)$, com base nos estudos da neurociência, é de utilizar esse mesmo elemento que é predominante nas produções da mídia - a emoção - nas práticas pedagógicas no âmbito escolar ou em outras situações envolvendo os diferentes profissionais, de modo que os alunos e a população se sintam mobilizados para aprender, refletir e desenvolver uma atitude crítica e criativa diante das produções midiáticas.

As HQ são aqui discutidas como meios e fins didáticos que podem ser utilizadas na escola (Alcantara
\& Bezerra, 2016; Fronza, 2016; Kawamoto \& Campos, 2014). A educação para o lazer a que nos referimos é baseada nos estudos de Marcellino (1987), portanto, como objeto de educação a ser tratado na escola, dentre outros âmbitos do lazer, de modo que os sujeitos possam refletir acerca de valores predominantes na sociedade atual, no intuito de buscar meios para se viver em uma nova ordem moral e intelectual, favorecendo mudanças no plano social. Assim, este trabalho tem como objetivo analisar a eficácia de uma proposta pedagógica que parte dos estudos da Comunicação Educativa (baseada na neurociência) e da educação para o lazer. A seguir trataremos dos procedimentos metodológicos que tornou possível realizar este objetivo.

\section{Material e método}

Esta pesquisa é de natureza qualitativa e baseada em uma experiência pedagógica, realizada a partir de revisão de literatura e pesquisa de campo, tendo como base Minayo (2019) ao se referir às pesquisas qualitativas, especificamente, indica serem pesquisas em que se busca o acesso aos significados, crenças, aspectos subjetivos produzidos pelos sujeitos.

A revisão de literatura foi baseada em Severino (2016) e envolveu a busca de referências sobre os estudos do lazer, HQ e da Comunicação Educativa, assim como também se utilizou de obras pré-selecionadas relacionadas a tais temas. O levantamento bibliográfico foi realizado dentro do intervalo de anos de 2012 a junho de 2018, na base de dados Scielo e utilizando palavras-chave nos idiomas espanhol e português. Abaixo as combinações feitas das palavras-chave e, entre parênteses, o número de referências encontradas. Palavras-chave em espanhol combinadas entre si: neurociencia, comunicación, cómics, educación física, enseñanza secundaria (25). Foram utilizadas as palavras Comics e supeheroes não combinadas, tendo resultado somente com a primeira (70). Outras combinações feitas foram a partir dos termos em português: histórias em quadrinhos and super-heróis (4) e histórias em quadrinhos (32). Outras combinações não tiveram resultados. Utilizou-se também os termos de busca "neurociência and educação" (15). Outras combinações em português/espanhol foram: "Comunicação educativa and lazer", "Comunicación educativa and ocio", Neurociencia and Comunicación educativa" e "Neurociência and Comunicação educativa", mas não foi possível identificar textos dentro dos critérios estabelecidos de busca. Os critérios de inclusão foram: a seleção de artigos dentro do intervalo de anos da pesquisa (2012-junho/2018) e material bibliográfico 
contendo no título ou no resumo indicações de que tratavam de aspectos relacionados à: 1) neurociência e suas interrelações com a Educação ou Comunicação educativa e 2) as HQ que tratassem de concepções e contribuições para o campo da educação ou da educação para o lazer nas diferentes disciplinas escolares. Foram selecionados textos nos idiomas português e espanhol e que estavam em formato PDF. Foi considerado um artigo sobre HQ como recurso didático voltado ao Ensino Médio, dada a especificidade do tema. Foram excluídos artigos que tratavam de neurociência, específicos de disciplinas escolares que não fosse a Educação Física ou de discussões sobre neurociência sem aplicabilidade no campo educacional ou que não estavam no intervalo de anos de 2012-junho/2018. Também foram excluídos artigos sobre HQ que tratavam de temas ligados à linguística ou a literatura sem ter como foco a aplicabilidade das HQ no âmbito escolar. Excluiu-se, ainda, os artigos que não estavam disponíveis na internet em formato PDF. Para as finalidades do presente texto, utilizou-se as referências que mais trouxeram contribuições para a análise dos dados da pesquisa de campo.

A experiência pedagógica foi realizada com 20 alunos do último ano do Ensino Fundamental ( $9^{\circ}$ ano) de uma escola pública da cidade de Piracicaba/SP, com idades entre 13 e 14 anos, e a partir das aulas de Educação Física. A escolha pela instituição onde foi realizada a pesquisa de campo deve-se ao fator de acessibilidade. A pesquisa foi aprovada pelo Comitê de Ética em Pesquisa do Brasil sob o protocolo: 75213417.2.0000.5507.

Inicialmente foi feito o convite para uma turma de alunos do $9^{\circ}$ ano do Ensino Fundamental da escola selecionada. Alguns alunos se manifestaram positivamente para participar da pesquisa e entregaram os termos de consentimento de acordo com os critérios de ética em pesquisa, outros alunos não entregaram os termos ou não quiseram participar da pesquisa, em princípio por não quererem se compromoter a entregar o termo de consentimento assinado por eles e pelos pais, mas participaram da aula. Assim, considerou-se como participantes da pesquisa os alunos que quiseram participar da investigação e entregaram os termos de consentimento (tanto o assinado por eles como pelos seus responsáveis). Três alunos foram agregados à pesquisa sendo os mesmos de outra turma de $9^{\circ}$ anos, sendo convidados pelo professor responsável pelas aulas de Educação Física, que justificou o convite pelo fato desses alunos serem bem participativos e, em seu julgamento, poderiam contribuir positivamente para a investigação. Os três alunos concordaram em participar da pesquisa e entregaram os termos de consentimento. Alguns poucos alunos que não participaram da pesquisa também não quiseram participar das aulas, mesmo mediante insistência do (a) professor (a) da pesquisa e do responsável pela turma.

A escolha por alunos do último ano do Ensino Fundamental deve-se ao fato de serem potenciais leitores de HQ e por estarem em um momento da fase escolar em que é possível introduzir elementos teóricos, de modo a terem acesso a conhecimentos para que possam realizar uma leitura qualificada das produções da mídia, da cultura de consumo e desenvolverem reflexões sobre os temas tratados relacionados ao corpo, aos valores éticos e morais, aos personagens de super-heróis, dentro de uma proposta de Comunicação Educativa e educação para o lazer. A pesquisa de campo foi realizada a partir de uma experiência pedagógica em um total de seis encontros com os alunos e nove aulas efetivas (cada encontro com os alunos era de aulas duplas. O primeiro encontro não foi uma aula propriamente dita, foi feita uma apresentação para verificar quais alunos participariam da investigação, utilizando uma aula somente e, no último encontro, foi também utilizada somente a primeira aula para o encerramento do trabalho, assim, em quatro encontros foram dadas oito aulas e mais a aula do último dia, totalizando 9 aulas). As aulas foram realizadas tendo como método de ensino a identificação do conhecimento prévio dos alunos e o confronto com o conhecimento sistematizado (Smolka, 2000). As estratégias de ensino utilizadas foram o debate/discussão e vivências a partir do tema das HQ de super-heróis. Abaixo uma descrição do que foi planejado e realizado nas aulas.

Encontro 2/Aulas 1 e 2: discussão/vivências sobre a interação com personagens estereotipados. Indicação por parte dos alunos dos tipos de sentimentos que puderam ser revelados ao lerem a HQ e se isso permite identificar se há compreensão e, sobretudo, se existe atitude de recusa dos alunos ante os estereotipos.

Encontro 3/Aulas 3 e 4: discussão/vivências sobre a interação com os super-heróis desde um ponto de vista corporal. Desenvolvimento de uma atividade em que os alunos se passariam por super-heróis, de modo a demonstrarem o que sentem desde um ponto de vista físico, de interação com outros corpos, e que repercurssões têm para eles esta experiência, gerando indiferença ou recusa, aceitação ou recusa da própria corporeidade.

Encontro 4/Aulas 5 e 6: orientações para a criação de HQ a partir de jornais e revistas. Os alunos constroem roupas a partir dos recortes de jornais e revistas. Nessa 
atividade o propósito foi os alunos terem oportunidade de expressar os sentimentos, de modo a exporem atitudes de recusa ou não diante dos estereótipos dos super-heróis.

Encontro 5/Aulas 7 e 8: os alunos elaboram um pequeno teatro em que são os próprios personagens das HQ de super-heróis. Nessa atividade o propósito foi de discussão/vivência sobre os valores éticos e morais que envolvem as HQ de super-heróis, relacionadas às ações dos super-heróis, tais como: salvar as pessoas, lutar contra o mal, ser um exemplo para as pessoas etc.

Encontro 6/Aula 9: os alunos avaliam o que compreendem acerca da experiência pedagógica realizada e fechamento das discussões.

$\mathrm{Na}$ experiência pedagógica foram feitas observações, anotações em diário de campo e também foi utilizado um gravador de voz para registrar as falas dos alunos participantes. As anotações no diário de campo foram referentes às observações das manifestações (verbais e gestuais) dos alunos nas aulas ministradas e dos acontecimentos/fatos ocorridos nas aulas, mediante os conteúdos propostos.

A escola em que a experiência pedagógica foi realizada aceitou a condução das aulas pelo (a) pesquisador (a) que foi também o (a) professor (a) principal da referida experiência. Além dele (a) mais dois professores auxiliaram a realização da experiência pedagógica.

A etapa de apresentação e análise dos resultados da investigação foi realizada mediante a avaliação da eficácia da experiência pedagógica. Inicialmente foi feita a interpretação dos dados, na tentativa de identificar os significados das ações dos alunos e, então, buscou-se compreender e analisar tais significados a partir do subsídio teórico da Comunicação Educativa e dos estudos de HQ e do lazer.

Os alunos foram identificados na pesquisa por número de modo a se manter o sigilo de seus nomes. Participaram da pesquisa 20 alunos todos do $9^{\circ}$ ano do ensino fundamental, sendo 7 do sexo masculino e 13 do sexo feminino e a idade entre 13 e 14 anos.

$\mathrm{Na}$ descrição e análise dos dados foi feita menção a cinco alunos individualmente $(1,8,2,5$ e 11$)$, que foram os mais participativos nas aulas e que foi possível identificá-los a partir das manifestações verbais ou das atividades realizadas nas aulas.

Tabela 1 - Dados sociodemográficos dos alunos participantes

\begin{tabular}{|l|l|l|l|}
\hline Aluno (a) & Sexo & Idade & Escolaridade \\
\hline 1 & masculino & 13 & $9^{\circ}$ ano/Fundamental \\
\hline 2 & masculino & 14 & $9^{\circ}$ ano/Fundamental \\
\hline 3 & masculino & 14 & $9^{\circ}$ ano/Fundamental \\
\hline 4 & masculino & 14 & $9^{\circ}$ ano/Fundamental \\
\hline 5 & masculino & 14 & $9^{\circ}$ ano/Fundamental \\
\hline 6 & masculino & 14 & $9^{\circ}$ ano/Fundamental \\
\hline 7 & masculino & 14 & $9^{\circ}$ ano/Fundamental \\
\hline 8 & feminino & 14 & $9^{\circ}$ ano/Fundamental \\
\hline 9 & feminino & 14 & $9^{\circ}$ ano/Fundamental \\
\hline 10 & feminino & 14 & $9^{\circ}$ ano/Fundamental \\
\hline 11 & feminino & 14 & $9^{\circ}$ ano/Fundamental \\
\hline 12 & feminino & 14 & $9^{\circ}$ ano/Fundamental \\
\hline 13 & feminino & 14 & $9^{\circ}$ ano/Fundamental \\
\hline 14 & feminino & 14 & $9^{\circ}$ ano/Fundamental \\
\hline 15 & feminino & 14 & $9^{\circ}$ ano/Fundamental \\
\hline 16 & feminino & 14 & $9^{\circ}$ ano/Fundamental \\
\hline 17 & feminino & 14 & $9^{\circ}$ ano/Fundamental \\
\hline 18 & feminino & 14 & $9^{\circ}$ ano/Fundamental \\
\hline 19 & feminino & 14 & $9^{\circ}$ ano/Fundamental \\
\hline 20 & feminino & 14 & $9^{\circ}$ ano/Fundamental \\
\hline
\end{tabular}




\section{Resultados e discussão}

Com relação às atividades e envolvimento dos alunos, destaca-se quatro tipos de atividades propostas que geraram nos alunos diferentes respostas. No contato inicial com os alunos eles deram indicações de que os super-heróis de HQ fazem parte de seu universo de referência, no entanto, o acesso a esses super-heróis é mais decorrente dos filmes lançados, baseados nas HQ. Vários alunos comentam sobre os super-heróis da empresa Marvel (Homem-Aranha, Capitão América, Hulk, Homem de Ferro, Thor), por exemplo:

Homem de Ferro: musculoso, alto/altura média, normal, branco, moreno, olhos escuros, calmo, esnobe, alcóolatra (Aluno 1), fuma charuto (Aluno 1), malandrão, pegador.

Capitão América: forte, musculoso, grande e magro, loiro, olhos azuis, calmo, rápido, inteligente, decente, direito, solitário.

Hulk: verde, alto, musculoso, desproporcional, parece extraterrestre, mãos e braços grandes, fúria, estressado, perturbado, um pouco equilibrado.

Nota-se que há alguns aspectos de contradição nas características dos personagens indicadas pelos alunos, tais como o homem de ferro ser ao mesmo tempo pegador/namorador, esnobe, alcóolatra e "fuma charuto" como afirma o aluno 1. Essas duas últimas adjetivações foram atribuídas, ou seja, tentando construir uma imagem negativa ou cômica do super-herói (Aluno 1) para contrapor o sentido de que o super-herói tem a imagem de "bom moço", de alguém que chama a atenção das mulheres. Também sobre o Capitão América a avaliação feita envolveu algumas associações como a consideração de que sua imagem corporal, física está associada a valores como decência, dignidade, a uma qualidade humana. Por fim, há uma oposição construída, de que o personagem Hulk, por suas características, se mostra mais um personagem fictício do que real. Ao contrário dos outros dois personagens - o Homem de Ferro e o Capitão América, que para as referências dos alunos se mostram mais próximos de uma pessoa do cotidiano, desejadas, referências de valores ou de aparência.

Essas qualificações indicadas pelos alunos correspondem a discussão de Ferrés i Prats, Masanet-Jordá e Lazo (2013) que identificam a carência de pesquisas e estudos em educação midiática acerca das emoções, que envolve os significados e sentidos atribuídos às imagens e mensagens produzidas pela mídia. Os elementos que mobilizam os sujeitos a agirem e a construírem referências de padrões corporais de beleza são entendidos como não importantes ou relevantes para as análises realizadas, sobretudo na Espanha, país de origem dos autores. Os alunos participantes da presente investigação ao avaliarem a forma corporal dos super-heróis revelaram certos padrões corporais de beleza que são construídos culturalmente, fazendo com que alguns super-heróis sejam avaliados de modo próximo a pessoas do cotidiano como o caso do Homem de Ferro e o Capitão América e outros possuem uma forma mais fictícia, como o caso do Hulk. Esse tipo de avaliação contribui para que os alunos ao identificarem essas características tenham consciência de tais referências expressas pelos super-heróis, de modo a desenvolverem um aprendizado que é mobilizado pelos significados, sentidos e emoções (Ferrés i Prats, 2000, 2014; Ferrés i Prats, Masanet- Jordá \& LAZO, 2013; Fonseca, 2016).

A segunda atividade foi uma estratégia repetida nos encontros 3, 4 e 5. Trata-se de um circuito de movimentos para o "treinamento das habilidades de super-heróis". Esse circuito foi composto por três estágios: 1) deslocamento correndo, passando pelos equipamentos: cones, minijump (equipamento usado na ginástica, os alunos saltam sobre uma base de material elástico entrelaçado), arcos e medicine ball para arremesso (equipamento utilizado na ginástica para treinamento de força); 2) caminhar sobre a fita do slackline (trata-se de um esporte, em que a pessoa se equilibra sobre uma fita e 3) dar socos no saco de boxe. Os alunos puderam experimentar o circuito de diferentes formas, passando pelos equipamentos correndo mais forte, mais devagar, ficando um tempo em cada equipamento, também foi dada a liberdade para que eles ficassem um tempo maior no equipamento que mais gostaram; isso no nosso entendimento favoreceu a participação deles na aula. O slackline inicialmente consideramos que pudesse ser a prática de maior desafio aos alunos, dado que para um iniciante é extremamente difícil manter o equilíbrio na fita. No entanto, procuramos no encontro inicial fazer a demonstração do uso dos equipamentos, fato que pode ter contribuído para encorajar os alunos a tentarem fazer. A maioria dos alunos experimentou os três estágios do circuito. Os alunos, ao vivenciarem o circuito dos super-heróis, se manifestaram ao final das aulas de modo a fazerem uma comparação entre eles e os super-heróis, alguns alunos disseram: "eu sou podre" (Aluno 1), "estou cansado" (Aluno 1), "faltou ação" (Aluna 8), "os super-heróis podem voar" (Aluna 8), outros alunos não identificados se manifestaram mexendo a cabeça positivamente, de modo a concordar com esses alunos citados, outros riram dos comentários feitos. 
Nessa avaliação, os alunos demonstraram ter clareza de que suas habilidades e características são incompatíveis com as dos super-heróis.

Nessa segunda atividade podemos identificar que há indicativos de que os alunos (1 e 8) aprenderam conhecimentos acerca da cultura corporal de movimento (habilidades, novas modalidades esportivas como aprender sobre o slackline, a andar e se equilibrar sobre uma corda), mas também sobre o contexto dos super-heróis, ao fazerem uma comparação de si próprios com os super-heróis, seja no sentido de afirmar valores ou de reconhecer que são diferentes dos super-heróis, inclusive fisicamente e em termos de capacidades e habilidades físicas. Esse resultado vai ao encontro de alguns pressupostos da Comunicação Educativa, fundamentada aqui principalmente nos estudos de Ferrés i Prats (2000, 2014). Segundo o referido autor, para uma boa comunicação é necessário o comunicador, no caso aqui, o professor, utilizar-se de múltiplos recursos e que sejam adequados para a situação e o público envolvido. Sendo o uso de recursos audiovisuais importantes para a situação de ensino, por mobilizarem as emoções. $\mathrm{Na}$ experiência pedagógica esse processo se deu pela inclusão nas aulas das HQ e dos personagens de super-heróis, que favoreceu a introdução de situações que foram vivenciadas pelos alunos, viabilizando a eles a experimentação de uma situação concreta, vivida corporalmente. Isso, na nossa avaliação, contribuiu para canalizar as emoções e sentimentos no sentido de fazerem comparações entre eles e os super-heróis das HQ, sendo tais comparações indícios de atitude reflexiva por parte dos alunos, ao se manifestarem expressando que se sentiam cansados, que não eram tão ágeis (como os super-heróis).

A aprendizagem demonstrada pelos alunos da pesquisa corresponde a outros estudos identificados na revisão de literatura em situações de aulas com uso de HQ, tais como: Fronza (2016) que utilizou a HQ em aulas de História e Kawamoto e Campos (2014) que utilizaram as HQ como recurso didático para o ensino do corpo humano em anos iniciais do Ensino Fundamental. Segundo essas duas referências, as HQ potencializam o aprendizado pelo formato e elementos dos quadrinhos, sendo que Fronza (2016) reforça o elemento dos quadrinhos despertarem aspectos emocionais nos alunos e isso ser um fato favorável ao aprendizado. No caso da presente pesquisa esse processo educativo foi duplo porque o tema dos super-heróis das HQ foi base para a aula, mas os alunos experienciaram o tema a partir de uma atividade corporal, vivida, real, e a manifestação dos mesmos era sobre essa realidade vivida. Então aqui podemos considerar que: 1) as atividades vivenciadas corporalmente os instigaram ao aprendizado das habilidades corporais e 2) ao reconhecimento de que são diferentes dos super-heróis, dada a limitação em termos de velocidade, equilíbrio e resistência física. Assim, o processo de educação para o lazer, baseado em Marcellino (1897), ocorreu a partir do acesso dos alunos ao conhecimento do conteúdo fisicoesportivo, aqui representado pelo circuito de super-heróis e pela comparação dos alunos com os super-heróis dos quadrinhos, sendo tais personagens objeto de conhecimento para a aula vivenciada.

A terceira atividade que avaliamos importante na realização das aulas foi a construção das roupas de super-heróis. O (A) professor (a)-pesquisador (a) levou os materiais básicos, tais como: jornais, tesouras, fitas adesivas e os alunos fizeram as roupas. A primeira vez que fizeram as roupas foi no encontro 4 e, a segunda, no encontro 5 . A dinâmica da aula foi: dividir os alunos em grupos; os alunos que seriam os super-heróis deveriam se manifestar ou serem escolhidos pelos grupos formados; os membros do grupo ajudariam na criação das roupas e na confecção das mesmas. Os super-heróis contruídos no encontro 4 foram: Mulher-maravilha, Samurai e "Super Astro" (personagem inventado pelos alunos com habilidades de vários outros super-heróis). $\mathrm{O}$ aluno 2 teve a ideia de fazer um vilão ao invés de um herói. O vilão pensado foi o Thanos (personagem que tem de especial uma luva com espaço para a colocação de alguns diamantes. O propósito desse personagem é buscar todos os diamantes, assim poderá controlar o universo). No encontro 5 os alunos se dividiram em dois grupos, nesse dia, houve menos alunos presentes na aula, em decorrência do período do ano (já em etapa final das aulas) e também por ter sido uma semana de provas. Nesse dia os alunos se dividiram em dois grupos, um deles fez duas Mulheres-Maravilhas e o outro grupo fez a roupa (luva) do vilão Thanos.

Essa atividade da construção de roupas de super-heróis com jornais e fita adesiva tem correspondência com os estudos de Alcantara e Bezerra (2016) em termos de processo de incentivo a criatividade. Os autores destacam a importância do lúdico no processo de ensino e aprendizagem sobre a alimentação. Eles partem de orientações e discussões sobre a alimentação, utilizando o formato quadrinístico e abordando temas como o consumo e o desperdício de alimentos. Na experiência didática dos autores os alunos aprendem que a cozinha pode também ser o espaço da criança e que esta pode não apenas ajudar, mas também preparar e inventar/criar pratos deliciosos 
e saudáveis e de uma forma lúdica. Da mesma forma, os alunos da presente pesquisa ao construírem as roupas de super-heróis extraíram dos quadrinhos a referência dos super-heróis e de um vilão, e também criaram um novo super-herói, o que demonstra que os alunos vivenciaram a experiência de criação de um super-herói, indo além do previsto que era utilizarem os super-heróis já conhecidos dos quadrinhos. Esse fato indica que a atividade propiciou aos alunos a atitude criativa que é geradora de novos conhecimentos.

A quarta atividade que aqui fazemos destaque foi o teatro de HQ. Para essa atividade, foi apresentado aos alunos um exemplar de HQ da Garota-Aranha e feito um resumo da história: "ao final a super-heroína salva um outro super-herói na história (no caso o homem-aranha)", sendo enfatizado que esse final é sempre esperado nas histórias, já que é papel dos super-heróis salvarem as pessoas. Também foi dado ênfase ao aspecto de que tanto os personagens como o enredo e os elementos das HQ de super-heróis contribuem para o imperialismo da cultura norte-americana, colocando em evidência a superpotência dos Estados Unidos e os aspectos dessa cultura, tendo como base os estudos de Said (2011). Após as roupas estarem prontas, foi proposto aos alunos que criassem um enredo para a história, reunindo os personagens criados. Eles elaboraram uma situação envolvendo a perseguição do vilão Thanos pelas Mulheres-maravilhas, em uma espécie de brincadeira conhecida no Brasil como "pega-pega", sendo que a defesa do Thanos era lançar um "raio-laser" (para indicar o lançamento do raio-laser o aluno fazia um movimento com as mãos e falava alto que era o "raio-laser", assim teria o poder de paralizar as super-heróinas), no entanto, as duas alunas que fizeram a personagem não respeitaram a regra de ficarem paradas com o "raio-laser", o que fez o aluno que representou o Thanos demonstrar certa frustação ao final da atividade, já que as super-heroínas conseguiram chegar até ele e impedi-lo de continuar correndo.

Essa experiência mostra-nos que a história construída teve um desfecho similar às HQ de super-heróis, no caso as Mulheres-Maravilhas (Aluna 11 e outra aluna que participou da aula, mas não da pesquisa) vencendo o vilão Thanos (Aluno 5). No entanto, isso gerou frustração ao aluno 5, pois, para ele, as super-heroínas tinham que respeitar o combinado e ficarem paralizadas ao lançamento do "raio-laser", já que essa era a defesa do aluno que no jogo fugia de duas super-heroínas, ou seja, o aluno 5 reagiu emocionalmente e racionalmente, pois encontrou um argumento para justificar sua indig- nação de ter "perdido a batalha", já que as meninas que representaram as Mulheres-Maravilhas não respeitaram a "regra". Essa argumentação aponta também para a necessidade de diante de uma situação de interação ou de "jogo", como a situação vivida pela teatralização da HQ construída pelos alunos, os envolvidos precisam se pautar em valores que deem aos participantes condições igualitárias de participação, isso é fundamental para que a atividade ocorra. As alunas agiram motivadas a pegar o "vilão", se tivessem respeitado a regra do jogo talvez elas não teriam conseguido pegá-lo, no caso, se houvesse mais tempo seria possível discutir novamente as regras combinadas, de modo a trazer mais desafio para todos os envolvidos no jogo. Ao final da aula o professor (a) chamou a atenção dos alunos para a necessidade de se respeitar as regras do jogo combinadas para que todos possam participar e para que o jogo ocorra. Não havia mais tempo para uma outra vivência de atividade, foi possível observar que os alunos demonstraram ter entendido o ponto de vista do professor (a).

O jogo é um elemento da cultura composto por certas regras, propiciando aos jogadores a vivência de situações de se experimentar uma liberdade primeira, de distração e fantasia (Caillois, 2017). O caso aqui ocorrido leva-nos a refletir sobre a importância dos valores que são vivenciados a partir do jogo e o respeito às regras e aos jogadores. Essa construção de valores corresponde a educação para o lazer no sentido de se ter uma visão crítica de lazer e de sociedade (Marcellino, 1987), sendo necessária a construção de valores revolucionários para que haja uma mudança social efetiva, para que se tenha uma sociedade mais justa e igualitária. Isso pode ocorrer a partir da construção de valores em um jogo como esse vivenciado pelos alunos da pesquisa, pois essa é uma forma de aprendizado de valores sociais. Assim, a participação dos alunos indicam um ato de criticidade com relação ao jogo, inicialmente pela manifestação do aluno 5, ao argumentar com relação às regras não respeitadas pelas duas outras alunas, e também ao final, quando os envolvidos tanto o aluno 5 como as duas outras alunas, terem indicado compreensão com relação ao ponto de vista do professor (a).

No fechamento da experiência pedagógica foi ressaltando por parte do professor que as HQ são produções que refletem valores e significados da cultura norte-americana e que isso traz influências para os leitores acerca da forma corporal dos personagens e dos discursos dos mesmos que expressam valores sociais, por isso a proposta de aulas de se conhecer mais os super-heróis 
dos quadrinhos. Também foi ressaltada a importância dos alunos que não participaram ativamente das aulas da necessidade de reverem essa postura, de modo que tenham chances de aprender acerca dos temas tratados nas aulas de Educação Física. Alguns alunos se manifestaram dizendo sobre algumas atividades que mais gostaram como o slackline e que foi uma novidade o fazer as roupas de super-heróis.

Todas as situações que compuseram a experiência pedagógica demostram que o tema dos super-heróis nas aulas colaborou para a potencialização das emoções nos alunos envolvidos, viabilizando aos mesmos o acesso ao conhecimento para que pudessem fazerem novas relações, iniciadas pela canalização das emoções no sentido de instigar a reflexão dos conteúdos tratados e vividos a partir das aulas, gerando assim novos conhecimentos.

Talvez como forma de minimizar o problema da não participação de alguns alunos nas aulas, é necessário o uso de distintos recursos midiáticos nas aulas. Assim, é possível se fazer um levantamento prévio junto aos alunos, sobre os interesses dos mesmos com relação as produções da mídia em geral e o uso de recursos distintos, como sendo uma solução para que a aula tenha apoio e participação de todos.

Os limites dessa investigação deve-se ao fato de ser uma primeira tentativa de uma pesquisa realizada a partir de experiência pedagógica, tendo os subsídios teóricos da Comunicação Educativa e da educação para o lazer, sendo bem-vindas outras experiências em diferentes regiões do Brasil para a obtenção de mais dados acerca dessa aproximação teórica em aulas de Educação Física.

A experiência pedagógica aqui avaliada e narrada em forma de pesquisa descritiva também indica que houve o aprimoramento de um método de ensino, com base nas manifestações dos alunos 1, 8, 2, 5 e 11 diretamente e, dos demais alunos, indiretamente, pois demonstraram atenção e participação nos procedimentos metodológicos de ensino adotados.

O processo educativo desenvolvido viabilizou aos alunos o acesso e a produção de novos conhecimentos acerca dos super-heróis das HQ, da cultura corporal de movimento dando indícios do desenvolvimento de atitudes crítica e criativa. Espera-se, assim, que os alunos ao terem essa consciência e vivência dos conteúdos da aula de Educação Física possam incluir no seu dia a dia o hábito de realizar e apreciar as práticas corporais e reverem valores e conceitos acerca dos padrões corporais de beleza, dos elementos da cultura corporal de movimento e dos super-heróis das HQ.

\section{Referências}

Alcantara, C. S. de \& Bezerra, J. A. B. (2016). O lúdico, a escola e a saúde: a educação alimentar no gibi. Trab. educ. saúde, 14 (3), 889-904.

Brasil. (2014). Apenas 54,3\% dos jovens concluem o Ensino Médio até os 19 anos. Disponível em: <http://www.todospelaeducacao.org.br/reportagens-tpe/32163/apenas-543-dos-jovens-concluem-o-ensino-medio-ate-os-19-anos/. Acesso em: 02 dez 2016.

Betti, M. (2006). "Imagens em ação": uma pesquisa-ação sobre o uso de materias televisivas em programas de educação física do ensino fundamental e médio. Movimento, 12 (2), 95-120.

Caillois, R. (2017). Os Jogos e os homens: a máscara e a vertigem. Lisboa: Cotovia.

Darido, S. C. (2004). A educação física na escola e o processo de formação dos não praticantes de atividade física. Revista Brasileira de Educação Física e Esporte, 18 (1), 61-80.

Diniz, I. K. dos S., Rodrigues, H. de A. \& Darido, S. C. (2012). Os usos da mídia em aulas de Educação Física escolar: possibilidades e dificuldades. Movimento, 18 (3), 183-202.

Ferrés i Prats, J. (2000). Educar en una cultura del espetáculo. Barcelona: Paidós.

Ferrés i Prats, J. (2014). Las pantallas y el cerebro emocional. Barcelona: Editorial Gedisa.

Ferrés Prats, J., Masanet- Jordá, M. J. \& Lazo, C. M. (2013). Neurociencia y educación mediática: carencias en el caso español. Historia y Comunicación Social, 18, 129-144.

Fonseca, V. (2016). Importância das emoções na aprendizagem: uma abordagem neuropsicopedagógica. Rev. psicopedag., 33 (102), 365-384.

Fronza, M. (2016). As possibilidades investigativas da aprendizagem histórica de jovens estudantes a partir das histórias em quadrinhos. Educar em Revista, 60, 43-72.

Kawamoto, E. M. \& Campos, L. M. L. (2014). Histórias em quadrinhos como recurso didático para o ensino do corpo humano em anos iniciais do Ensino Fundamental. Ciênc. educ. (Bauru), 20 (1), 147-158.

Marcellino, N. C. (1987). Laz̧er e educação. 11 ed. Campinas: Papirus, 1987.

Minayo, M. C. et al. (2019). Pesquisa social: teoria, método e criatividade. Rio de Janeiro: Vozes.

Pires, G. (2002). Educaşão Física e o discurso midiático: Abordagem Crítico-Emancipatória. Ijuí: Editora Unijuí.

Rossi Filho, S., Origuela, M. \& Silva, C. L. da. (2016). Histórias em quadrinhos de super-heróis: educação para o lazer a partir de elementos da contemporaneidade. Revista Licere, 19 (29), 260-293.

Said, E. W. (2011). Cultura e imperialismo. São Paulo: Companhia das letras.

Severino, A. J. (2016). Metodologia do trabalho cientifico. 24ed. São Paulo: Editora Cortez.

Silva, C. L. da \& Ferrés i Prats (2019). Superhéroes y villanos en las clases de Educación Física. Revista de Ciencias de la actividad física, 20, 1-20.

Silva, C. L. da \& Ferrés i Prats, J (2020). Comunicación educativa y educación para el ocio en Educación Física escolar. Revista Licere, 23, 394-418.

Smolka, A. L. B. (2000). O (im)próprio e o (im)pertinente na apropriação das práticas sociais. Caderno Cedes, 20 (50), 26-40.

Submetido em: 13-1-2020

Aceito em:24-8-2020 